\title{
Capacitação de Gestores Públicos em Gerenciamento de Resíduos da Arborização Urbana
}

\author{
Training Public Managers in Management of Urban \\ Forestry Residues
}

RESUMO

Este trabalho apresenta um relato do processo de difusão da tecnologia gerada no programa de pesquisa Gestão de Resíduos da Arborização Urbana, desenvolvido no Laboratório de Movelaria e Resíduos Florestais do Departamento de Ciências Florestais da ESALQ-USP. A gestão de resíduos da poda e remoção é um problema para grande parte dos municípios do estado de São Paulo. Estudos anteriores realizados por esse grupo de pesquisa apontaram a necessidade de instrumentos que pudessem contribuir para a melhor formação de gestores públicos na elaboração dos planos de gerenciamento de resíduos da arborização urbana. Foi utilizada uma abordagem por foco na estruturação do conteúdo, organizado na forma de um manual técnico e considerando os diferentes portes e modelos administrativos dos municípios participantes. As oficinas foram organizadas de forma a integrar os municípios de cada região administrativa do estado, visando promover uma interação entre os técnicos, propiciando um ambiente favorável à continuidade da troca de informações e experiências. No total, no período de agosto de 2010 a junho de 2011, foram realizadas 4 oficinas, atendendo 52 municípios do estado, com 89 participantes, sendo $21 \%$ secretários municipais de meio ambiente, $70 \%$ técnicos na área, e os demais, técnicos operacionais, prefeitos e vice-prefeitos, dentre outros.

Palavras-chave: Gestão de resíduos. Resíduos florestais. Silvicultura urbana.

\begin{abstract}
This paper presents an account of the diffusion of technology generated in the research program "Waste Management of Urban Forestry”, developed at the Laboratory of Mobile and Waste Department of Forestry Forest Sciences ESALQ-USP. The management of waste from pruning and removal is a problem for most municipalities of São Paulo. Earlier studies by this research group, noted the need for instruments that can
\end{abstract}


contribute to better training of public managers in planning for waste management of urban trees. We used an approach focused on the structuring of content, organized in the form of a technical manual, and considering the different sizes and administrative models of the participating municipalities. The workshops were organized to integrate the municipalities in each administrative region of the state, to promote integration between technical experts, providing a favorable environment for the continued exchange of information and experiences. In total, from August 2010 to June 2011, four workshops were held, serving 52 municipalities in the state, with 89 participants, $21 \%$ municipal secretaries of the environment, $70 \%$ technicians, and other technical operating, mayors and vice-mayors, among others.

Keywords: Waste management. Forest residues. Urban silviculture.

\section{INTRODUÇÃO}

A partir da década de 1990, especialmente após a Rio 92, as questões ambientais ganharam cada vez maior importância na gestão municipal, levando a uma redefinição de ações e responsabilidades.

O município passa a ser um local privilegiado no tratamento dos problemas ambientais que afetam diretamente a qualidade de vida da população, resultado da aplicação do princípio "Pensar Global, Agir Local” e de uma série de políticas públicas como a Agenda 21, o Projeto Ambiental Estratégico Município Verde Azul, da Secretaria do Meio Ambiente do Estado de São Paulo, e a Política Nacional de Resíduos Sólidos, recentemente aprovada. É no território municipal que se manifestam os problemas ambientais e ao poder público municipal é delegada a responsabilidade pela solução de boa parte desses problemas.

A gestão ambiental municipal se estrutura com a definição e implementação de políticas públicas, planos e programas de gestão voltados para a solução de problemas específicos como o tratamento do esgoto sanitário, a redução e disposição do lixo, a arborização urbana, a recuperação de áreas degradadas, o uso da água e do solo, a educação ambiental e o controle da poluição do ar, dentre outros.

A política define as diretrizes gerais, os princípios que nortearão as ações, as prioridades e a estrutura organizacional, financeira e legal dos municípios, sempre em consonância com a política e a legislação estadual e federal. Já os planos de gerenciamento traduzem esses princípios gerais para as formas práticas de ação, articulando atividades técnicas, educativas, organizacionais, dentre outras, para a minimização ou solução total dos problemas, favorecendo uma maior sustentabilidade do ecossistema urbano.

Para que os governos municipais encontrem soluções viáveis do ponto de vista ambiental, social e econômico para os problemas ambientais é fundamental o entendimento preciso desses problemas, a definição de prioridades, o conhecimento de técnicas adequadas para seu enfrentamento, um comportamento institucional criativo, proativo, inovador e rapidez nas decisões políticas. É indispensável, ainda, a participação popular, de forma que o poder público compartilhe com a comunidade local as responsabilidades pelas decisões e implementação das ações. 
Assim, o enfrentamento dos problemas ambientais deixa de ser tratado de forma pontual e passa a ser abordado de maneira sistêmica, com base em ações integradas, monitoradas e participativas.

A poda e a remoção são práticas necessárias para o bom desenvolvimento das árvores nos espaços urbanos e sua compatibilização com os outros usos das vias públicas e espaço aéreo das cidades [7]. Entretanto, os resíduos dessas práticas podem se tornar um sério problema, a menos que a administração municipal disponha de um plano de gerenciamento de resíduos adequado às condições locais.

Em países como Alemanha e Estados Unidos, os resíduos da arborização urbana raramente são destinados a aterros. Em sua maior parte são transformados em matéria-prima ou em produtos como pellets para energia, composto orgânico e pequenos objetos de madeira.

Já no Brasil, a maioria das administrações municipais não sabe sequer quanto resíduo de arborização urbana é gerado em um determinado período de tempo e não conhece as características desses resíduos e seu potencial de valorização. Normalmente, o material é encaminhado para aterro ou lixão ou fica a cargo do cidadão a sua destinação. Nesse caso, a queima a céu aberto e o descarte em terrenos baldios, beiras de estradas e cursos d'água são as formas mais comuns de destinação.

Essas formas de destinação representam sempre um risco, contribuindo para a degradação da paisagem urbana, redução na qualidade do ar, problemas de saúde pública e inutilização de matéria-prima que poderia ser usada em atividades econômicas capazes de gerar novos postos de trabalho e renda, resultantes do surgimento de negócios locais [5].

Poucos municípios têm inovado nas formas de abordagem do problema e aproveitado esses resíduos para diferentes fins, transformando com criatividade um problema em oportunidade.

A gestão dos resíduos da arborização urbana é de responsabilidade do poder público municipal, cabendo a ele a elaboração e implementação do plano de gerenciamento.

Um plano de gerenciamento bem elaborado evita gastos desnecessários com armazenagem, transporte, tratamento, disposição final e remediação de impactos negativos causados pela adoção de soluções inadequadas.

Ações pontuais, sem planejamento e sem compromisso, não costumam dar bons resultados ou ter continuidade e isso prejudica a imagem do governo municipal e do próprio município. $\mathrm{O}$ plano permite a implementação das ações de forma articulada ao longo do tempo, independente da política partidária. Isso resulta em maior segurança para o cidadão sobre a aplicação dos recursos e a qualidade dos serviços recebidos.

Esse é o contexto no qual se estruturou a oficina Formação de Gestores Públicos: Gestão de Resíduos da Arborização Urbana, oferecida pelo Laboratório de Movelaria e Resíduos Florestais do Departamento de Ciências Florestais da ESALQ-USP, relatada neste trabalho. 


\section{HISTÓRICO}

Uma característica marcante nas atividades científicas do Laboratório de Movelaria e Resíduos Florestais da ESALQ-USP é o desenvolvimento, predominantemente, de pesquisa aplicada. Esse tipo de pesquisa tem como principal motivação a produção de conhecimento para aplicação mais ou menos imediata na solução de problemas concretos $[1,2]$.

A definição do problema de pesquisa nasce, assim, da observação e reflexão sobre a realidade e atrelado à necessidade de difusão dos seus resultados para a sociedade.

O desenvolvimento de um modelo de gestão para resíduos da arborização urbana teve início em 2008, a partir da demanda de várias prefeituras do estado que procuravam o laboratório buscando soluções para a correta disposição dos resíduos, o que resultou numa série de projetos integrados em um programa de pesquisa.

A partir dessa demanda social e dada a escassez de informações e trabalhos científicos que ajudassem a responder à questão, o problema foi proposto como estudo de caso na disciplina LCF 699, Gerenciamento de Resíduos Florestais, do curso de graduação em Engenharia Florestal. Esse trabalho resultou num diagnóstico sobre as soluções de manejo dos resíduos da arborização urbana adotadas pelas prefeituras no estado de São Paulo, publicado posteriormente no $16^{\circ}$ Simpósio Internacional de Iniciação Científica da Universidade de São Paulo (SIICUSP).

Nesse mesmo ano, iniciou-se o projeto de pesquisa Gestão de Resíduos da Arborização Urbana, que teve por objetivo quantificar e caracterizar os resíduos da poda e remoção de árvores no município de Piracicaba (SP), avaliar a possibilidade de valorização em diferentes produtos e analisar o modelo de gestão adotado pela prefeitura municipal; a partir dessas informações detalhadas, desenvolver um sistema de gerenciamento que pudesse servir como modelo para os demais municípios, considerando as peculiaridades locais. Esse projeto resultou na tese de doutorado da engenheira florestal Ana Maria de Meira, pelo Programa de Pós-Graduação em Recursos Florestais da ESALQ-USP [5].

Paralelamente, um grupo de estagiários e pós-graduandos do Laboratório de Movelaria e Resíduos Florestais trabalhou no desenvolvimento de produtos a partir dos resíduos madeireiros. Nesse projeto - que contou com apoio dos programas Aprender com Cultura e Extensão e Ensinar com Pesquisa, ambos da USP - foram realizados estudos de caracterização física da madeira das dez espécies mais utilizadas na arborização do município de Piracicaba. Foram desenvolvidos brinquedos e objetos utilitários e decorativos que permitissem o uso dos resíduos madeireiros dos galhos e fustes como matéria-prima para os projetos municipais de capacitação para o trabalho e para o fomento de pequenos empreendimentos $[3,4,6]$.

Os resultados desse projeto foram difundidos para a comunidade local através da Oficina de Aproveitamento de Resíduos da Arborização Urbana, financiada pelo Fomento às Iniciativas de Cultura e Extensão da USP (FICEx), atingindo principalmente aos agentes multiplicadores vinculados a ONGs e aos programas da própria prefeitura municipal.

Um estudo específico, financiado pela Fundação de Apoio à Pesquisa do Estado de São Paulo (FAPESP), tratou do desenvolvimento de um modelo de gerenciamento 
adequado à realidade dos pequenos municípios, carentes em recursos financeiros e principalmente em recursos humanos capacitados.

Após três anos de construção e consolidação de conhecimento na área, foi elaborado o projeto Oficina de Formação de Gestores Públicos: Gestão de Resíduos da Arborização Urbana, que também contou com o apoio da Pró-Reitoria de Cultura e Extensão da USP, através do FICEx, com o objetivo de difundir o modelo de gestão desenvolvido nos projetos, capacitando os técnicos para aplicação em seu município.

\section{OBJETIVOS}

Através de oficinas técnicas de curta duração, propôs-se:

1. Capacitar os técnicos das prefeituras dos municípios do Estado de São Paulo, responsáveis pela gestão de resíduos sólidos urbanos, no desenvolvimento de planos de gerenciamento de resíduos da arborização urbana;

2. Criar uma rede social que possibilitasse a troca de experiências entre os participantes, a partir da realidade administrativa de cada município;

3. Promover o estreitamento das relações entre a universidade e as prefeituras municipais e a integração das atividades de ensino, pesquisa e extensão na solução de problemas apresentados pela sociedade.

\section{CONTEÚdO E MÉTODO DE DESENVOLVIMENTO DAS OFICINAS}

As oficinas tiveram sua estrutura organizada em dois módulos de quatro horas de duração, totalizando oito horas de atividade. No primeiro módulo, os participantes foram apresentados ao problema e à base conceitual necessária para o perfeito entendimento da questão. No segundo módulo, os participantes discorreram brevemente sobre os problemas e oportunidades identificados no manejo dos resíduos no seu município. A partir dessa realidade trazida pelo grupo, foi apresentado e discutido o método proposto para elaboração do plano de gerenciamento, baseado em políticas públicas e ações integradas que permitam a redução da geração, a valorização dos resíduos gerados e a disposição como solução emergencial.

$\mathrm{Na}$ estruturação das informações e conteúdo foi utilizada uma abordagem por foco, organizada na forma de um manual técnico. As oficinas foram organizadas, ainda, de forma a integrar os municípios de cada região administrativa do estado, visando promover uma integração entre os técnicos, propiciando um ambiente favorável à continuidade de troca de informações e experiências. Dessa, forma, cada oficina foi oferecida para um grupo de municípios de uma dada região administrativa.

As oficinas foram divulgadas através de convites com o programa enviados diretamente para cada prefeitura. Posteriormente, foram identificadas as secretarias responsáveis pelos serviços de arborização, poda, remoção e gestão de resíduos sólidos e encaminhado convite diretamente aos técnicos da área. 
Foram realizadas quatro oficinas com oito horas de duração cada, focando principalmente as regionais administrativas de Campinas, São Carlos/Araraquara, Ribeirão Preto e Sorocaba. Ao final de cada encontro realizou-se uma avaliação; com isso, foi possível, durante o seu desenvolvimento, aprimorar o processo de capacitação e o próprio modelo de gerenciamento proposto, que foi ajustado ao longo dos encontros, através da confrontação com as diferentes realidades dos municípios.

\section{MÓDULO 1 - BASE CONCEITUAL}

O módulo foi conduzido pela profa. dra. Adriana Maria Nolasco e o programa priorizou a consolidação de conceitos e conhecimentos fundamentais para a elaboração de planos de gerenciamento de resíduos. Foi abordado o conceito de resíduo a partir do senso comum, das definições legais e normativas, assim como suas implicações prático-funcionais. Isso permitiu a discussão sobre as responsabilidades do técnico e do poder público em relação às soluções adotadas e as questões éticas envolvidas na gestão de resíduos. Uma análise histórica sobre a evolução dos modelos de gestão de resíduos permitiu identificar os árbitros na condução desses processos, as soluções priorizadas em cada modelo e as consequências ambientais, sociais e econômicas da implementação dessas soluções.

Foram discutidos os desafios para se elaborar e implementar planos de gerenciamento de resíduos nos municípios e ações para sua viabilização, considerando as limitações financeiras e de recursos humanos, os interesses políticos e a falta de continuidade das ações propostas em função da dinâmica eleitoral. Foi objeto de discussão a responsabilidade da administração municipal, do setor privado e do cidadão, de acordo com princípios éticos e determinações legais. Por fim, foi apresentado o método e os princípios gerais para elaboração de planos de gerenciamento de resíduos.

\section{MÓdULO 2 - ELABORAÇÃO DE PLANOS DE GERENCIAMENTO DE RESÍDUOS DA ARBORIZAÇÃO URBANA}

Esse módulo foi conduzido pela dra. Ana Maria de Meira e tratou da apresentação do método proposto para elaboração dos planos de gerenciamento de resíduos da arborização urbana e, de forma interativa, de todos os pontos que compõem o plano e sua relação com a estrutura política e administrativa dos municípios. O plano é composto pelas seguintes atividades:

1. Definição da equipe coordenadora da elaboração e implementação;

2. Definição dos objetivos gerais do município em relação ao problema;

3. Realização do diagnóstico de geração e caracterização dos resíduos;

4. Definição de prioridades de ação;

5. Definição de metas para cada prioridade;

6. Seleção das ações/soluções a serem implementadas para se atingir cada meta; 
7. Organização das ações em programas integrados de redução da geração, valorização e tratamento e disposição;

8. Procedimentos para implementação;

9. Procedimentos para monitoramento dos programas/ações;

10. Reformulação para melhoria constante do plano.

\section{RESULTADOS OBTIDOS}

Ao todo, foram realizadas quatro oficinas, atendendo as regiões administrativas de Campinas, São Carlos/Araraquara, Ribeirão Preto e Sorocaba.

$\mathrm{Na}$ região de Campinas, houve a participação de 15 municípios e 27 técnicos. Pela região de São Carlos/Araraquara, participaram 7 municípios e 15 técnicos. Por Ribeirão Preto, foram 24 municípios e 38 técnicos. Por Sorocaba, 6 municípios e 9 participantes.

Predominou a participação de pequenos municípios - com até 50 mil habitantes que correspondeu a $63,5 \%$ do total, seguidos pelos municípios de grande porte - acima de 100 mil habitantes -, com $23 \%$. Os municípios de médio porte corresponderam a 13,5\% dos participantes.

A participação predominante de municípios de pequeno porte apontou uma grande carência de soluções e capacitação de recursos humanos em gerenciamento de resíduos sólidos adequadas à realidade administrativa e técnica desses locais. Isso foi, ainda, elucidado pelas discussões durante as aulas. Esses municípios enfrentam grandes desafios políticos e operacionais. Dentre eles, podemos citar:

" A falta de políticas públicas para a arborização urbana. Na maioria dos casos, cabe ao cidadão definir as espécies arbóreas que serão plantadas em frente à sua residência ou estabelecimento comercial/industrial, como podar, quando retirar e a destinação dos resíduos dessas operações. Isso influencia diretamente no volume de resíduos gerados e na sua destinação, o que comumente se faz em algum terreno baldio, beira de estrada e outros locais inadequados;

" A falta de recursos humanos e financeiros para elaborar e implementar programas de gerenciamento de resíduos sólidos de maneira geral. Grande parte desses municípios conta com um ou dois funcionários responsáveis por todas as ações ambientais;

" A despreparo dos políticos (prefeitos, secretários e vereadores) para a definição de leis e políticas públicas eficientes e contínuas, que estabeleçam ações, recursos e responsabilidades na implementação das soluções possíveis.

Nos médios municípios, a situação parece ser bastante semelhante. Já nos grandes, identificamos um pouco mais de infraestrutura para elaboração e implementação dos planos de gerenciamento de resíduos da arborização urbana.

Em relação à função exercida nas prefeituras, a maioria dos participantes $-70 \%$ - fazia parte do corpo técnico responsável pela elaboração de programas de ação e sua operacionalização nas secretarias de meio ambiente; 21 \% foram diretores ou secretários de meio ambiente; os demais, funcionários de outros setores, da CETESB, vice-prefeitos 
e técnicos do Programa Município Verde Azul da Secretaria do Meio Ambiente do Estado de São Paulo.

$\mathrm{Na}$ avaliação dos participantes, as oficinas propiciaram: estímulo ao desenvolvimento de política municipal para gerenciamento de resíduos da arborização urbana; soluções técnicas para redução da geração e valorização dos resíduos de poda e remoção de árvores, além de mecanismos de monitoramento para uma legislação efetiva; estreitamento da relação entre a universidade e as prefeituras; aproximação entre os técnicos das prefeituras participantes, o que permitiu identificar problemas comuns e possibilidades de solução, baseadas nas experiências já implantadas em alguns municípios participantes.

Os primeiros resultados aplicados começaram a surgir. Alguns municípios nos procuraram para sanar dúvidas na elaboração de seus planos e na implementação de algumas soluções, principalmente em projetos de compostagem.

A partir dessa primeira experiência, o projeto será expandido visando atingir inicialmente um número maior de municípios do estado de São Paulo. Para isso, estão se estabelecendo parcerias com o Programa Município Verde Azul, com a Coordenadoria de Assistência Técnica Integral da Secretaria da Agricultura do Estado de São Paulo (CATI) e com o Conselho Regional de Engenharia e Arquitetura (CREA).

\section{CONSIDERAÇÕES FINAIS}

A atualidade do tema, dada a aprovação da Política Nacional de Resíduos Sólidos, e a necessidade de sua implementação nos municípios no curto prazo foram fatores motivadores para a participação no curso.

Mais que disseminar conhecimentos acumulados, as oficinas tiveram o importante papel de confrontar o modelo conceitual construído para gerenciamento dos resíduos da arborização urbana, através da pesquisa, com os desafios da realidade política, social, econômica e operacional das prefeituras municipais e profissionais dos técnicos participantes do curso, gerando reelaborações do modelo também como forma de construção do conhecimento científico.

Ao mesmo tempo, cumpriu sua função de processo educativo pela via da aprendizagem, produção e disseminação do conhecimento. Despertou o interesse dos alunos de graduação dos cursos de Engenharia Florestal e Gestão Ambiental da ESALQ-USP, integrados ao projeto através de atividades de estágio, iniciação científica e participação na organização das oficinas.

O contato com a realidade dos municípios e condições de trabalho dos técnicos mostrou-se um importante instrumento para a construção de uma postura crítica e cidadã para esses alunos, ampliando sua percepção sobre a corresponsabilidade na solução dos problemas ambientais. 


\section{REFERÊNCIAS BIBLIOGRÁFICAS}

[1] APPOLINÁRIO, F. Dicionário de metodologia científica: um guia para a produção do conhecimento científico. 1. ed. São Paulo: Atlas, 2004. 304 p.

[2] BARROS, A. J. S.; Lehfeld, N. A. S. Fundamentos de metodologia: um guia para a iniciação científica. 2. ed. São Paulo: Makron Books, 2000. 122 p.

[3] GATTI, R. C.; ARTHUSO, J.; NOLASCO, A. M.; ULIANA, L. R. Densidade básica e aparente da madeira de galhos de onze espécies utilizadas em arborização urbana. In: SIMPÓSIO INTERNACIONAL DE INICIAÇÃO CIENTÍFICA DA USP, 17., 2009, Piracicaba. Anais... [S.I.: s.n.], [2009?]. . CD-ROM.

[4] GATTI, R. C.; ARTHUSO, J.; NOLASCO, A. M.; ULIANA, L. R. Aproveitamento dos resíduos da arborização urbana na produção de pequenos objetos de madeira. In: SIMPÓSIO INTERNACIONAL DE INICIAÇÃO CIENTÍFICA DA USP, 17., 2009, Piracicaba. Anais... [S.I.: s.n.], [2009?]. . CD-ROM.

[5] MEIRA, A. M. Gestão de resíduos da arborização urbana. 2010. 179f. Tese (Doutorado em Recursos Florestais)-Escola Superior de Agricultura Luiz de Queiroz, Universidade de São Paulo, Piracicaba, 2010.

[6] NOLASCO, A. M.; MEIRA, A. M. Quantificação dos resíduos da arborização urbana na cidade de Piracicaba-SP. In: ENCONTRO NACIONAL, 5., ENCONTRO LATINO AMERICANO SOBRE EDIFICAÇÕES E COMUNIDADES SUSTENTÁVEIS, 3., 2009, Recife. Anais... [S.I.: s.n.], [2009?]. 1 CD-ROM.

[7] PIVETA, K. F.; SILVA FILHO, D. F. Arborização urbana. Boletim Acadêmico. Jaboticabal: UNESP, 2002. 69 p. Série Arborização Urbana.

\section{AGRADECIMENTOS}

Agradecemos a Pró-Reitoria de Cultura e Extensão da Universidade de São Paulo que, através do Fundo de Fomento às Iniciativas de Cultura e Extensão, financiou as oficinas.

A toda a equipe do Laboratório de Movelaria e Resíduos Florestais do Departamento de Ciências Florestais da ESALQ-USP que tornou possível a concretização desse projeto.

ADRIANA MARIA NOLASCO professora doutora do Departamento de Ciências Florestais da Escola Superior de Agricultura "Luiz de Queiroz" da Universidade de São Paulo (ESALQ-USP) - CP o9 - Piracicaba-SP - CEP 13418-9oo - e-mail:amnolasc@usp.br.

ANA MARIA DE MEIRA engenheira florestal e educadora ambiental do programa USP RECICLA - ESALQ-USP - e-mail: ammeira@usp.br.

RENATA CAROLINA GATTI graduanda em Engenharia Florestal pela ESALQ-USP - e mail: renata.gatti@usp.br. 